\title{
Geografía de la fragmentación en el periurbano de Quito: un análisis de las nuevas centralidades Cumbayá- Tumbaco y San Antonio de Pichincha
}

Cristian Serrano. Facultad Latinoamericana de Ciencias Sociales, Quito, Ecuador. Gustavo Durán. Facultad Latinoamericana de Ciencias Sociales, Quito, Ecuador.

RESUMEN | La configuración socioespacial de una ciudad en expansión ha generado una nueva geografía en la periferia urbana. Como resultado, la ciudad tiene una estructura funcional más compleja, donde se producen nuevas centralidades. Mediante un análisis cuantitativo en función de Indicadores Locales de Asociación Espacial (LISA) y el uso de Sistemas de Información Geográfica (SIG), se construyeron indicadores de centralidad y fragmentación, analizándose los elementos que conforman la estructura del espacio periurbano. En dos casos bajo estudio, se determinó un espacio central conformado por una variedad de bienes y servicios distribuidos en los antiguos subcentros y localizados a lo largo de un corredor terciario. Además, se analizó la división territorial y social del espacio en términos de fragmentación, para estudiar cómo evoluciona un espacio central y qué características tiene el espacio periurbano. Finalmente, mediante los casos analizados se concluye la presencia de una nueva geografía urbana fragmentada, en proceso de evolución.

PALABRAS CLAVE | expansión urbana, periferia urbana, geografía urbana.

ABSTRACT | The socio-spatial configuration of an expanding city has generated a new geography in the urban periphery. Therefore, the city has a more complex functional structure where new centralities are produced. Through a quantitative analysis based on Local Indicators of Spatial Association (LISA) and Geographic Information Systems (GIS), centrality and fragmentation indexes were developed, and elements contained in the structure of the urban periphery were analyzed. The central space was identified, which is composed of goods and services distributed in older subcenters and located along a tertiary corridor. In addition, we analyzed territorial and social division by fragmentation in order to study how central space evolves and which characteristics periurban space possesses. Lastly, the analyzed cases allow us to conclude the presence of a new fragmented urban geography in evolution.

KEYWORDs | urban sprawl, urban periphery, urban geography. 


\section{Introducción}

La expansión a gran escala de las ciudades que se originó a partir de la década de los ochenta ha modificado la estructura urbana, llevándola de ser compacta y monocéntrica, a expandida y difusa. Con ello se ha alterado la estructura funcional de las ciudades, generándose nuevos espacios atractivos para la población en la periferia. El auge de la ciudad exterior (Soja 2000, p. 355) se debe principalmente a la globalización y reestructuración económica, generadas por la desindustrialización, el desarrollo capitalista y una economía descentralizada, la cual surgió cuando los servicios y las economías de aglomeración empezaron a formar parte del nuevo ambiente urbano (De Mattos, 1999). Parte de este proceso ha sido la relocalización de bienes y servicios en la periferia de las ciudades y una mayor accesibilidad a los centros urbanos, la cual se incrementó por el uso del automóvil y la red de infraestructura vial distribuida hacia zonas rurales. Diferentes subcentros periféricos se han incorporado así a la dinámica urbana. La periferia produce nuevos espacios atractivos para la población, evidenciados en grandes estructuras, en la concentración del trabajo y equipamientos producidos por la acumulación de capital (Ciccollela \& Mignaqui, 2009). Como lo indica Harvey (2012), la acumulación de capital en la periferia "generó un nuevo modo de vida, basado en la producción y comercialización de nuevos productos" (p. 28), lo que ha conformado unidades residenciales para clases elitistas (los denominados suburbios), vaciando los centros de las ciudades.

Los procesos que impactaron en la estructura monocéntrica de la ciudad fueron la suburbanización, el incremento de nuevas vías, el aumento de movilidad de las personas que decidieron habitar lejos del centro y la relocalización de la industria. A partir de esto, cambió el paisaje y la morfología urbana y se expandió la ciudad, desde su forma conocida como "mancha de aceite", hacia una urbe de "archipiélagos", extensa y dispersa (Ciccollela, 1999). La expansión de la ciudad significó extender los límites urbanos hacia las zonas rurales, con elementos separados y dispersos, con bajas densidades poblacionales en un territorio extenso y "con características de dispersión y recentralización de elementos a escala metropolitana” (Gutiérrez \& García, 2007, p. 3).

Estos nuevos límites, conocidos como "bordes periurbanos", dificultan la delimitación de la ciudad y dividen la parte urbana de la rural (Ávila, 2009; Cortés, 2012; Díaz, 2011; Entrena-Durán, 2006; Hidalgo \& Borsdorf, 2009; Indovina, 2004; Toro, Velasco \& Niño, 2005). El borde periurbano funciona como receptor de residencias en el medio rural, atrae mayor cantidad de bienes y servicios que se recentralizan por las actividades que concentran (Gutiérrez \& García, 2007) e incrementa los flujos por motivos económicos, sociales, laborales, etcétera, puesto que "la gente abandona las zonas urbanas, hacia las zonas suburbanas y zonas rurales, lejos de los centros urbanos" (Ávila, 2001, p. 109).

Si bien en la periferia anglosajona la expansión urbana ha generado una organización socioespacial elitista, en América Latina la periurbanización fue provocada por diferentes actores, fundamentalmente clases medias y altas, que se localizaron de acuerdo con sus intereses personales y posibilidades económicas. Esta forma de 
suburbanización surgió a medida que mejoraron los ingresos personales de dichos grupos, generando consumo de suelo lejos del centro y bajas densidades poblacionales (De Mattos, 2010). En este marco, la periferia urbana en muchas ciudades de la región tiene un carácter fragmentado, dada la generación de diversos subcentros periurbanos como resultado de la globalización, del capital que continúa acumulándose, y del asentamiento de distintos estratos sociales en territorios rurales. El efecto ha sido el desarrollo de un modelo de ciudad dual en las periferias que incluye el incremento de distancias y desigualdades sociales (Prévôt-Schapira, 2001). Esta lógica de "ciudad dual" en un espacio "periférico central" (Gutiérrez \& García, 2007) es motivo de nuestra investigación, debido a que el capital acumulado produce centralidades en zonas externas a la ciudad compacta, ocasionando una manifestación espacial del proceso de periurbanización en el cual se entrelazan diferentes actividades económicas y formas de vida características, tanto en ámbitos urbanos como en rurales (Ávila, 2001, p. 109).

Ante esta problemática, el presente artículo tiene la intención de analizar el espacio periurbano configurado por las nuevas centralidades periféricas de la ciudad de Quito, respondiendo a la siguiente pregunta: ¿qué sucede con los procesos de fragmentación en el espacio periurbano a medida que se genera una nueva centralidad?

$\mathrm{Al}$ respecto, nuestra hipótesis es que la acumulación de capital en el periurbano produce altos niveles de centralidad, materializados a través de bienes y servicios, y reduce la fragmentación socioespacial. Son las nuevas centralidades las que reorganizan el territorio y lo transforman, y mantienen articulado el espacio periurbano.

\section{Nuevas centralidades y fragmentación en el contexto de la ciudad difusa: una aproximación teórica}

\section{Definiendo al espacio periurbano y las nuevas centralidades}

El centro, un espacio en constante cambio cuando se habla de ciudades, es analizado en geometría como un punto base que sirve para trazar una circunferencia y que geométricamente denota un espacio euclidiano equidistante hacia cualquier punto de todos sus lados. El centro representa la importancia de algo respecto de todo lo que lo rodea, y al relacionarlo con el urbanismo adquiere el significado de espacio principal (Paris, 2013). A partir de él se despliega la estructura de la ciudad y del territorio y, además, es el espacio más aventajado, porque concentra los bienes, servicios y equipamientos que permiten el adecuado desarrollo de la ciudad. Alrededor del centro se distribuyen las actividades económicas agrícolas a partir del principio de accesibilidad, lo que lleva a la demanda por tal cualidad (Cagmani, 2005). De allí que los sitios más cercanos al centro posean mayores niveles de calidad de vida y sean los más buscados por distintos tipos de actividades.

En torno al centro se encuentra la periferia como "territorio que se empieza a urbanizar por partes alrededor de la ciudad consolidada" (Arteaga, 2005). La periferia es el espacio geográfico opuesto al centro pero anexo al mismo, el más alejado del núcleo urbano y con menos ventajas de localización, con servicios y equipamientos deficientes y actividades diversificadas, lo que obliga a sus residentes a estar en constante relación con el centro de la ciudad (Arteaga, 2005). En estas 
condiciones, la periferia es el sitio más dinámico de la ciudad y se encuentra en constante transformación, características que lo hacen atractivo para acumular capital y desarrollar nuevos proyectos inmobiliarios y urbanísticos.

Para E. W. Soja (2000), la migración de varias actividades centrales a la periferia y la dispersión suburbana originan un nuevo desarrollo territorial de las ciudades, el cual genera nuevos lugares y funciones centrales en sitios suburbanizados y no consolidados que han alterado la morfología urbana compacta. Es un fenómeno que el autor definió como exópolis. Su análisis tiene como punto de partida la suburbanización de las periferias que modificó el modelo monocéntrico de ciudad, proceso provocado -en su parecer- por el incremento de la movilidad (mayor uso del automóvil) y que reconfiguró las periferias, permitiendo que "el campo y la ciudad sean más accesibles, al menos potencialmente” (p. 341). De igual manera, señala, la desindustrialización hizo que la empresa se relocalizara lejos del centro y se concentrara en la periferia, la cual, a su vez, comenzó a funcionar como nuevo subcentro por la alta densidad de empleo en ella y su conectividad con el centro de la ciudad.

Si bien los cambios en la ciudad posmoderna provocaron, según indica Soja (2000), que "se vacíen grandes núcleos y la producción se localice en la periferia" (p. 345), la "reestructuración de la forma urbana" (p. 333) fue diferente en las ciudades latinoamericanas. Para Indovina (2004), surge un modelo de ciudad "dispersa o difusa", inserto en un espacio agrícola (de pobreza), caracterizado por "bajas densidades residenciales, con viviendas unifamiliares, centros comerciales y otros espacios de actividad" (Gutiérrez \& García, 2007, p. 3). La ciudad difusa contiene una periferia urbana de pobreza, informalidad, ausencia de infraestructura y escasos equipamientos; en contraposición, presenta ocasionalmente enclaves de sectores sociales de altos ingresos (Frediani, 2009).

Como resultado de la expansión de la ciudad compacta hacia un modelo de ciudad difusa en las periferias, existen dos lógicas de funcionamiento en los territorios urbanos periféricos de América Latina. Por un lado, se tiene el caso del mercado como agente organizador, el cual, a través de mecanismos informales o privatizadores, da como resultado asentamientos localizados fuera del centro, según la lógica de menor precio de suelo. En los casos de los sitios más baratos, tienen un mínimo de servicios y se configuran como zonas populares, por lo general cercanas al centro (Abramo, 2012; Carrión, 2003; Rojas, 2004). Por otro lado, las políticas de urbanización y un débil papel del Estado en la regulación de los mercados de suelo han producido un tipo de periferia poblada de asentamientos destinados a los sectores de menores recursos, mediante mecanismos que expulsan a la población de "desposeídos" hacia asentamientos de vivienda social, donde "la periferización es la lógica del desarrollo urbano" (Carrión, 2000, p. 187). En este caso, la planificación urbana influye en la toma de decisiones para ubicar, invertir y construir diferentes elementos en ese espacio (Cuenya, 2011).

Bajo ambas lógicas se analiza el término 'periurbano' como fenómeno en el cual las personas abandonan las zonas urbanas y se relocalizan en la periferia, hacia zonas rurales, urbanizando el entorno y transformando su morfología. La periferia urbana es también el sitio donde los flujos poblacionales se han incrementado, como consecuencia de la deslocalización de actividades productivas, inmobiliarias y terciarias 
(Arteaga, 2005; Ávila, 2001). El periurbano "no es solo aquella corona más externa del continuo urbano", sino que -como se mencionó- tiene su origen en el entorno rural, donde se evidencia de manera espectacular la "penetración urbana" (Ávila, 2001).

Para Hidalgo y Borsdorf (2009), la periferia urbana se desarrolla cerca de antiguos núcleos rurales difusos o, como señala Indovina (2004), se "difunde a partir de centros habitados preexistentes" (p. 50), por lo que atrae bienes y servicios, entendidos como los producidos en distintas actividades económicas y ofertados por empresas o personas para satisfacer las necesidades de los consumidores y necesarios para abastecer la demanda de la población (Cagmani, 2005).

El espacio periurbano está configurado por diferentes actores que se localizan en los nuevos subcentros (núcleos), originando que diferentes espacios secundarios empiecen a ejercer influencia en sus respectivos entornos (Gallo, Garrido \& Vivar, 2010, p. 7). Se ha convertido en un espacio polifuncional con características centrales y muy atractivo para la población. Para Paris (2013, p. 16), el espacio periurbano concentra más de una función, aglomera elementos y es el lugar donde coexisten el comercio, servicios, ocio, cultura y, sobre todo, lucha y resistencia (p. 16); es un "lugar de centralidad" donde se aglutinan funciones centrales (p. 49).

Hidalgo y Borsdorf (2009, p. 182) indican que los núcleos del periurbano "son entidades diferenciadas funcionalmente, que tienen su propia centralidad", por los elementos que aglomeran y por su semejanza con el centro principal a una escala reducida. La aglomeración de elementos que satisfacen la demanda local del periurbano produce nuevas centralidades: i) por el uso que se realiza en dicho espacio; ii) por las ventajas que proporciona a la población debido a su localización lejos del centro compacto; y iii) por las economías de aglomeración que surgen en ese espacio en el que convergen flujos de todo tipo.

Los bienes y los servicios que se concentran en los núcleos influyen en el entorno, en particular por los traslados casa-trabajo y diversos tipos de relaciones más o menos complejas (Cagmani, 2005). Bienes y servicios buscan ventajas de localización y se distribuyen a lo largo de los ejes viales que conectan diferentes subcentros y localidades cercanas, produciendo los llamados "corredores terciarios" (Bazant, 2008; Muñiz, Sánchez \& García-López, 2015; Pradilla, 2010; Pradilla \& Pino, 2004). De igual manera, tienden a distribuirse cerca de sitios residenciales ya establecidos, debido a que atienden a la población residente, tienen una localización ventajosa por estar cerca de infraestructuras viales principales y están bien conectados con la periferia, abasteciendo las necesidades principalmente de hogares pudientes. Por eso "si los hogares más pudientes se dispersan por la ciudad, un conjunto de empleos y servicios los seguirían” (Rodríguez, 2012, p. 77).

De acuerdo con Pradilla (2010), los corredores terciarios tienen la capacidad de atraer usuarios a escala metropolitana, urbana o local, generando un espacio céntrico orientado a las actividades económicas y a usuarios domésticos individuales. Analizaremos dicho lugar como una nueva centralidad, ya que se constituye con nuevos desarrollos inmobiliarios, como oficinas, sitios comerciales, espacios de ocio y entretenimiento y viviendas de sectores altos y medios. En este debate examinamos una dimensión morfológica de las nuevas centralidades, que genera 
un escenario de competitividad con el centro principal (Shearmur, Coffey, Dabé \& Barbonne, 2006; Tella, 2005). Se trata de un espacio "apetecible", ya que las áreas que en un momento pertenecieron a la periferia ahora son atractivas para la localización de elementos urbanos como los señalados y para la construcción de viviendas de alta densidad, destinadas a familias que prefieren habitar cerca de los nuevos espacios centrales (Rojas, 2004).

Las nuevas centralidades conforman "complejas formas de urbanización” (Tella, 2005 , p. 4), por la variedad de elementos que contienen en su estructura, los cuales "dan lugar a un efecto de fragmentación de las antiguas áreas integradas" (Pradilla, 2010, p. 522). Para Tella (2005), las nuevas centralidades se desarrollan sobre "fragmentos territoriales dispersos", estableciendo un nodo con el que se vincula el resto de fragmentos. De esta manera, "las nuevas centralidades periféricas (...) se convierten en el complemento indispensable para el mosaico de fragmentos residenciales o laborales especializados" (López, Gonzáles, Parrilla, Ruiz, J. \& Ruiz, T., 1996, p. 8), debido a que los fragmentos dependen de la influencia de las nuevas centralidades para mantenerse vinculados y evitar ser dispersados.

\section{Periferia fragmentada y fragmentos especializados}

A finales de la década de los ochenta surge el concepto de fragmentación, en respuesta a los fenómenos sociales y espaciales que las ciudades presentaron cuando la pobreza aumentó de manera significativa y nuevas formas de segregación se empezaron a evidenciar a partir de la violencia y el miedo. En este sentido, es un proceso que ha surgido en el periurbano de la ciudad latinoamericana y ha modificado los patrones tradicionales de su configuración socioespacial (Salcedo \& Dear, 2012), fomentando que las interacciones espaciales y sociales ya no funcionen en un espacio homogéneo y unívoco, sino que se dividan.

La fragmentación -noción utilizada para "analizar los procesos que hicieron estallar la ciudad" (Prévôt-Schapira, 2001, p. 38)- es una consecuencia "casi inevitable de la globalización y la competencia entre ciudades que aceleran la circulación del capital"; constituye un proceso que tiene lugar tanto en los centros urbanos como en las periferias o en sitios de interés que modifican la estructura de su entorno, y es considerada una consecuencia negativa del desarrollo urbano, porque expresa desorden, separación, desconexión y exclusión (Escolano-Utrilla, López-Escolano \& Pueyo-Campos, 2018, p. 188). Produce aumento de las desigualdades socioeconómicas y espaciales a partir de los procesos de periferización de áreas centrales y centralización de áreas periféricas (Tella, 2005, p. 4).

En este contexto, se evidencia una estructura dual con "lógicas de separación, extensión y nuevas fronteras urbanas, que establecen distinciones entre los diversos grupos sociales" (Jirón \& Mansilla, 2014, p. 6). Según Janoschka (2002), esto se debe a que "los procesos de urbanización privada y la tendencia al aislamiento de complejos habitacionales y comerciales" (p. 13) han sido encabezados por grupos de mayores ingresos, que se han insertado en territorios periféricos agrícolas y han producido "islas de riqueza" (p. 25).

A mayor profundidad, el periurbano disperso y dividido alberga en cada fragmento una porción de clases sociales distantes o, como lo indica Prévôt-Schapira 
(2001), "la proximidad de ricos y pobres, pero en espacios herméticamente cerrados, lo que establece relaciones asimétricas entre las dos partes de la ciudad” (p. 39).

Los espacios cerrados contribuyen a una "fractura y separación social del espacio", donde conviven diferentes estratos sociales (Link, 2008, p. 17), en cuya configuración ha sido partícipe el mercado. De esta manera, son las nuevas centralidades las que albergan una división socioespacial en su estructura, y empiezan a contener una estratificación social diferenciada.

El incremento de las "islas de riqueza" en el periurbano genera espacios "aislados" de la trama urbana, pero con un fuerte nivel de centralidad, formando nuevos puntos de interés para las elites (Tella, 2005). Las islas se convierten en fragmentos especializados funcionalmente por sus atributos de centralidad, constituyendo un soporte de una actividad exclusiva (López et al., 1996, p. 7). Tales fragmentos están aislados funcional y físicamente, pero se mantiene un vínculo entre los diferentes flujos de los fragmentos (Escolano-Utrilla et al., 2018). Generan nuevas dinámicas, como la atracción de ciertos servicios urbanos especializados, afectaciones en el mercado del suelo, relocalización de ciertos lugares de empleo, etcétera (Caprón \& González, 2006, p. 68).

Para indicar cómo se produce y divide el espacio, en esta investigación analizaremos la fragmentación a través de dos dimensiones de análisis, expresadas por la división territorial y la distancia social (Prévôt-Schapira, 2001):

- La división territorial está referida a la distribución espacial de enclaves o islas, asentamientos humanos, desarrollos residenciales, nuevos artefactos de la globalización, etcétera, que tienen lugar en la periferia, en bajas densidades y dispersos. Analizamos las discontinuidades morfológicas que se presentan debido al patrón disperso de urbanización y que difiere del patrón tradicional compacto. En este sentido, la dimensión indica una "división social del espacio" (Prévôt-Schapira \& Cattaneo Pineda, 2008), por las distancias sociales que son el resultado de la baja densidad residencial en los fragmentos.

- La distancia social o "separación o distanciamiento social en la ciudad" (Link, 2008, p. 17), referida a espacios territorialmente consolidados pero socialmente distanciados, que generan lógicas de exclusión y marginalidad social (PrévôtSchapira, 2001). Como consecuencia de la "excesiva homogeneidad (...) y baja densidad de los nuevos asentamientos” (López et al., 1996, p. 7) en el espacio periurbano, se generan sitios independientes y exclusivos (aislados), donde la distancia social es la que induce a la fragmentación. Esta dimensión indica que los sitios "exclusivos" son los que producen distanciamiento social entre clases sociales que conforman el periurbano; es decir, se ha producido una suburbanización de estratos altos y medios en territorios tradicionales dispersos (rurales) de clase baja, que ha contribuido a "fragmentar la totalidad de la trama social urbana (...), y generar situaciones de aislamiento entre las clases y de vulnerabilidad a la exclusión social" (Katzman \& Retamoso, 2005, p. 137). 


\section{Quito: ciudad con subcentros periféricos}

Esta investigación pretende desarrollar el tema de la fragmentación urbana en relación con una ciudad de la región que se encuentra en fase de desarrollo, donde ya comienzan a evidenciarse los procesos de las grandes metrópolis. Como caso se propone al periurbano del Distrito Metropolitano de Quito (DMQ), capital del Ecuador, cuyas características incorporan el desarrollo de nuevas centralidades que empiezan a ejercer cambios morfológicos en el territorio.

Se seleccionó el DMQ por el desarrollo demográfico importante que tuvo a partir de los ańos sesenta. Se define como una ciudad metropolitana en desarrollo por sus características físicas expansivas de baja densidad e inequitativas; uso urbano de territorios rurales; y la proliferación de patrones urbanísticos conformados por urbanizaciones cerradas y dispersas que generan la fragmentación del territorio urbano, entre otras (Secretaría de Territorio Hábitat y Vivienda, 2012). Del mismo modo, fue seleccionado por contener nuevas centralidades y porque su dinámica territorial se está ampliando hacia las periferias urbanas, conformando una ciudad difusa con "articulaciones ente lo urbano y lo rural (...) [y] múltiples vínculos con los cantones colindantes" (Instituto de la Ciudad, 2013, p. 8).

\section{Metodología}

Realizamos un análisis cuantitativo y comparativo entre dos estudios de caso seleccionados de la ciudad de Quito que miden su nivel de centralidad, a la vez que examinamos la evolución espacial y social de la fragmentación que la caracteriza (período 2001-2010).

\section{Casos seleccionados}

Para el análisis seleccionamos las nuevas centralidades localizadas en el periurbano de Quito, las cuales cumplen con los siguientes requisitos: localizarse en la periferia de la ciudad seleccionada; contener bajas densidades poblacionales; tener alta conectividad con el centro principal y con los diferentes subcentros; localizarse en un corredor terciario; desarrollarse en un antiguo subcentro; y contener artefactos de la globalización, como conjuntos habitacionales cerrados, centros comerciales, bienes y servicios, entre otros.

Para la selección de los casos en estudio, se realizó un análisis exploratorio en la periferia de la ciudad compacta de Quito y se identificaron los posibles subcentros con las características antes mencionadas (figura 1). Se dio prioridad a las parroquias rurales cercanas al área urbana, ya que disponen de mayor accesibilidad en tiempos de recorrido hacia el centro consolidado y tienen como atributo principal la disposición de un corredor terciario que incluye gran variedad de bienes y servicios. 


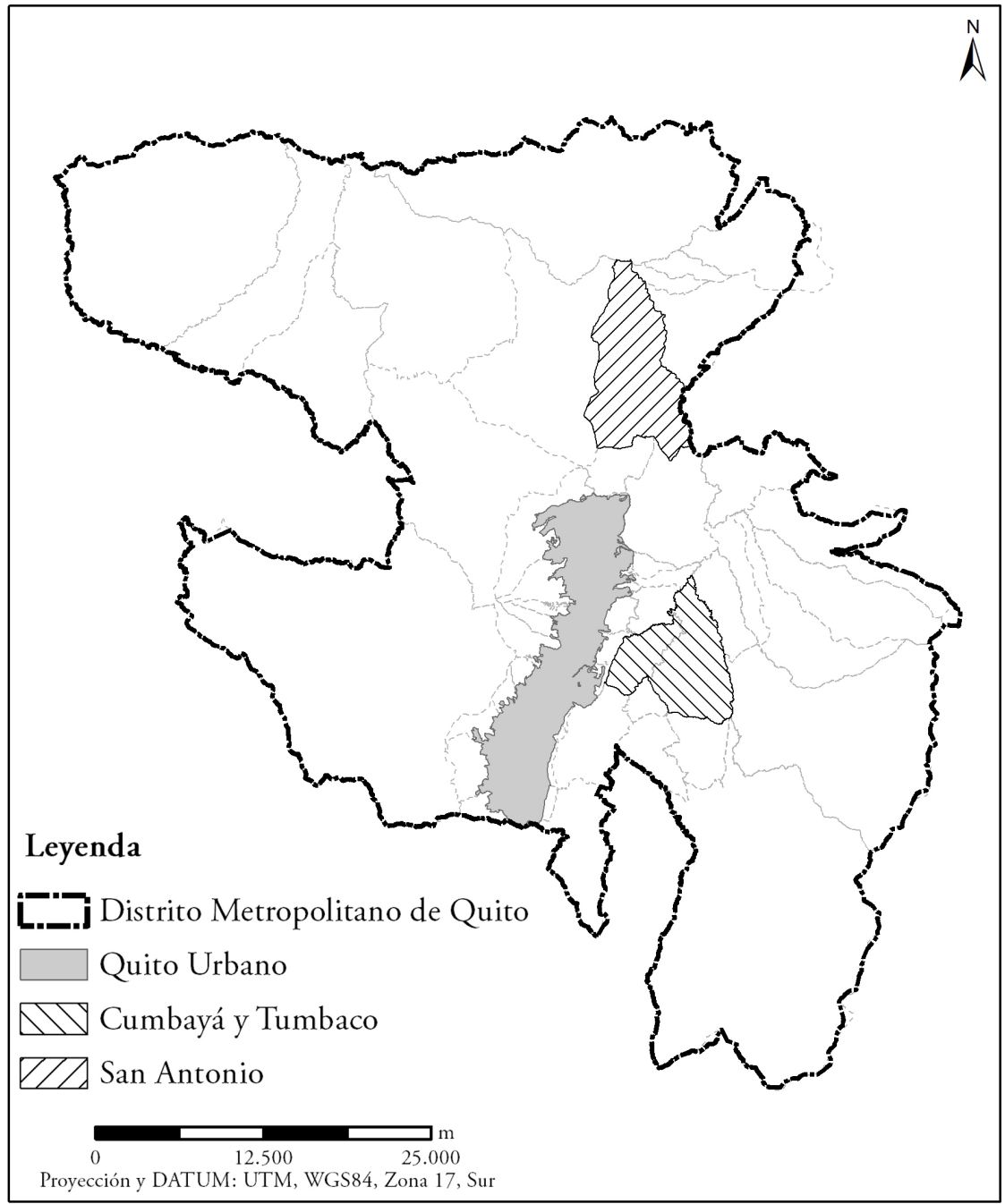

FIGURA I | Localización Cumbayá-Tumbaco y San Antonio

FUENTE: ELABORACIÓN PROPIA

Como estudios se seleccionaron dos centralidades localizadas en el periurbano de Quito. En primer lugar, las parroquias Cumbayá y Tumbaco, consideradas para este caso como una sola centralidad, ya que las dos conforman una "centralidad existente" y ambas están localizadas en un corredor terciario especializado en actividades comerciales. Nuestro interés es entender la centralidad en su estructura funcional, mas no con sus límites administrativos. Se realizó la comparación con la nueva centralidad de la parroquia San Antonio, ya que es considerada como una "centralidad en formación" (Cuenin \& Silva, 2010), especializada en la actividad turística. Ambos casos se han integrado a la dinámica metropolitana a través de la 
expansión de la ciudad. De igual manera, los dos casos comparados están en proceso de suburbanización y la proliferación de nuevos desarrollos residenciales en ellos está en constante aumento.

\section{Aspectos técnicos}

Se construyeron tres indicadores mediante técnicas geoespaciales con datos georreferenciados. Se utilizaron datos a nivel de sector censal de cada zona, cuya información sociodemográfica fue analizada, obtenida y procesada a partir de los software Redatam versión 5, QGIS 2.14 y Geoda 1.8.8.

En primer lugar, en el cálculo del indicador de aglomeración, se aplicó la metodología de Glendening (2012) para la delimitación de centros en función de la concentración de bienes y servicios en un determinado espacio, la cual utiliza Indicadores Locales de Asociación Espacial (LISA) y sIG. El objetivo fue recurrir a la distribución de bienes y servicios en cada estudio de caso para analizar su aglomeración y el área de influencia sobre el territorio. Como fuente de información secundaria se ocupó la base de datos de la Licencia Metropolitana Única para el ejercicio de Actividades Económicas 2016 (LUAE) del DMQ e información de la plataforma web Open Street Map, que contienen la distribución de bienes y servicios localizados en la ciudad.

En este proceso calculamos clústers espaciales y ponderados obtenidos a través de la suma de bienes y servicios contenidos en áreas hexagonales. Las áreas hexagonales hacen referencia a la distancia que los usuarios están dispuestos a recorrer para alcanzar un bien o servicio, representan la aglomeración de bienes y servicios en el espacio, y se distribuyeron cubriendo cada caso en su totalidad. Al ser entidades geométricas ayudan a la interpretación del espacio, delimitándolo y ayudando a representarlo geográficamente.

Una vez analizadas las zonas de aglomeración de bienes y servicios, se determinó su nivel de centralidad con un rango que va desde $0 \%$ para zonas sin centralidad, siendo espacios que no tienen influencia en su entorno para atraer flujos poblacionales o de algún tipo, y 100\% para el espacio con mayor centralidad, debido a que es el que tiene mayor accesibilidad, mayor número de bienes y servicios y el sitio mejor localizado (tabla 1). Al delimitar este espacio central, se puede conocer qué nivel de centralidad contiene respecto a otros espacios del área de estudio.

\begin{tabular}{|l|l|}
\hline \multicolumn{1}{|c|}{ NIVEL DE CENTRALIDAD (\%) } & \multicolumn{1}{c|}{ DESCRIPCIÓN } \\
\hline 1 a 10 & Bajo \\
\hline 10 a 25 & Medio bajo \\
\hline 25 a 50 & Medio \\
\hline 50 a 75 & Medio Alto \\
\hline 75 a 100 & Alto \\
\hline
\end{tabular}

TABLA I | Nivel de centralidad

FUENTE: ELABORACIÓN PROPIA

Para complementar la metodología, se propuso un índice que mide la influencia del espacio central en función de su tamaño y de los bienes y servicios que se concentran 
en él. El proceso consistió en calcular el Área de la Zona Central (AZC), siendo esta la zona con mayor centralidad (75\% a $100 \%)$, ya que es donde se aglomera la mayor cantidad de bienes y servicios. La Azc se dividió para el Área Total de la zona de estudio (AT) y se multiplicó por 100, debido a que nos interesa conocer el área que cubre (en porcentaje) o proporción de la zona central que comprende (para volver comparativos a los casos). A este cociente lo denominamos Capacidad Máxima Territorial de Centralidad (СмTC), siendo el área de influencia o tamaño de la zona central máxima en el territorio y la que contiene mayor cantidad de bienes y servicios. El indicador es útil para comparar casos, puesto que ayuda a analizar la morfología del territorio. Indicamos que si el смтC es mayor, mayor es la influencia en su entorno.

$$
C M T C=\frac{A Z C}{A T}
$$

Donde:

CMTC: capacidad máxima territorial de centralidad.

AZC: área con nivel de centralidad del 75\% al 100\%.

Ат: área total de la zona de estudio.

En segundo lugar, se obtuvo un indicador de densidad residencial para los años 2001 y 2010, analizando la "segmentación y dispersión del espacio urbano" (Jirón \& Mansilla, 2014) construido a partir de la clasificación de Bazant (2008), que determina los siguientes tipos de zonas: de territorio rural (altamente fragmentadas); dispersas y atomizadas (medianamente fragmentadas); en compactación (fragmentación baja); y compactas (sin fragmentación) (tabla 2).

\begin{tabular}{|l|l|l|}
\hline \multicolumn{1}{|c|}{ DESCRIPCIÓN } & \multicolumn{1}{|c|}{ VIVIENDAS/HA } & \multicolumn{1}{c|}{ NIVEL FRAGMENTACIÓN } \\
\hline Territorio rural & 1 a 10 & Alta \\
\hline Dispersa y atomizada & 10 a 20 & Media \\
\hline Compactación & 20 a 50 & Baja \\
\hline Compacto & $>50$ & Sin Fragmentación \\
\hline
\end{tabular}

TABLA 2 Fragmentación de acuerdo a la clasificación de Bazant (2008)

FUENTE: ELABORACIÓN PROPIA

$$
\text { Densidad residencial }=\frac{\# \text { viviendas }}{\text { hectárea }}
$$

La técnica consistió en analizar el número de sectores censales de acuerdo con su nivel de fragmentación, para hacerlos comparativos; de ello se obtuvo la proporción correspondiente a cada caso en función del total de sectores censales que presenta cada uno, para identificar los sectores censales que han cambiado su fragmentación. El indicador fue analizado a través de SIG e información a nivel de sector censal, por el detalle desagregado que presenta a nivel urbano. Los sectores censales permiten 
conocer la densidad por sector censal, y en función de eso se identificó el nivel de fragmentación de cada caso en estudio.

Finalmente, para interpretar la fragmentación social se realizó un indicador de "distancia social" que permitió identificar fragmentos de estratos sociales consolidados, analizando la autocorrelación espacial y el índice de Moran. La autocorrelación espacial establece el grado de concentración o dispersión de una variable en el espacio (Acevedo \& Velásquez, 2008, p. 15), mientras que el índice de Moran detecta si hay o no autocorrelación espacial entre variables e identifica clústeres de forma localizada (Molinatti, 2013), y la manera en que se distribuyen en el espacio.

Según establece Prévôt-Schapira (2001), las distancias sociales se evidencian en la medida en que se diferencian los estratos sociales y se modifica la convivecia entre ellas en un espacio reducido. Si bien el indicador es algo novedoso, ya que la distancia social es compleja de medir, nuestra interpretación apunta a identificar los fragmentos sociales mediante clústeres o aglomerados de población con características sociales similares, de acuerdo con el grado de similitud entre ellos o sector ocupacional al que pertenecen.

Se examinó la evolución del indicador entre los ańos 2001 y 2010, y se analizaron sectores censales mediante sig y la clasificación de Goldthorpe (1993) como base, la cual "combina categorías ocupacionales comparables" y clasifica a las clases sociales en clase de servicios, clase intermedia y clase obrera (Regidor, 2001, p. 14). Se realizó un mapeo de la variable de grados ocupacionales de los censos y se los clasificó para determinar las clases sociales en cada caso (tabla 3). Como fuente de información secundaria para los dos últimos indicadores se utilizó los censos de población y vivienda 2001 y 2010 del Ecuador, aplicando para ello el software Redatam.

\begin{tabular}{|l|l|}
\hline \multicolumn{1}{|c|}{ GRADO OCUPACIONAL } & \multicolumn{1}{c|}{ CLASIFICACIÓN } \\
\hline Directores y gerentes & Clase alta \\
\hline Profesionales científicos e intelectuales & Clase alta \\
\hline Técnicos y profesionales del nivel medio & Clase media \\
\hline Personal de apoyo administrativo & Clase media \\
\hline Trabajadores de los servicios y vendedores & Clase media \\
\hline Ocupaciones militares & Clase media \\
\hline Oficiales, operarios y artesanos & Clase media baja \\
\hline Operadores de instalaciones y maquinaria & Clase media baja \\
\hline Ocupaciones elementales & Clase media baja \\
\hline Agricultores y trabajadores calificados & Clase media baja \\
\hline
\end{tabular}

TABLA 3 | Clasificación según grado ocupacional

FUENTE: ELABORACIÓN PROPIA

El proceso del indicador se dividió en tres partes. En la primera se espacializó la variable de clases ocupacionales mediante los sectores censales, para lo cual se realizó una clasificación según el grado ocupacional, en un primer intento por analizar las clases sociales. En segundo lugar, se analizó la variable espacializada mediante el software GeoDa, a fin de medir el índice de Moran; el resultado permitió identificar 
la localización de las clases alta, media y media baja, según los clústeres obtenidos. En último lugar, se identificaron las zonas con fragmentación a partir del grado ocupacional identificado en el paso dos. El análisis fue realizado mediante sIG, ponderando de acuerdo con los siguientes criterios:

1. Fragmentación con peso 3 (alta): se refiere al nivel más alto de fragmentación social según el grado de ocupación. Se ha clasificado los clústeres bajo-alto y alto-bajo con un valor 3 , debido a que indican valores bajos de concentración, rodeados por otros valores altos, o valores altos rodeados de valores bajos. La interpretación de este nivel indica que existe un fragmento de clase social distinto inserto en un clúster de otra clase social (de acuerdo con su grado ocupacional). Se trata de clústeres que se han polarizado en esta zona.

2. Fragmentación con peso 2 (media): se refiere a un nivel de fragmentación medio según el grado de ocupación. Los clústeres bajo-bajo y sectores "no significantes" (LISA_P=O) son asignados con un valor de 2, puesto que contienen concentraciones bajas y espacios dispersos donde no se aglomera población. En este espacio la concentración de la variable es baja y dispersa, por lo que interpretamos que la fragmentación es media.

3. Fragmentación con peso 1 (baja): se refiere a un nivel de fragmentación bajo de acuerdo con el grado de ocupación. Los clústeres alto-alto han sido clasificados con un valor de 1 , puesto que contienen zonas muy concentradas de la variable; por ende, una fragmentación baja por tratarse de zonas homogéneas.

\section{Nuevas centralidades periurbanas: Cumbayá-Tumbaco y San Antonio de Pichincha}

\section{Los casos en estudios}

La nueva centralidad de Cumbayá-Tumbaco se localiza en la zona oriental del DMQ. Es considerada como una centralidad comercial existente o conformada, por la variedad de bienes y servicios que se han aglomerado en torno a la avenida Interoceánica, dotando de un alto nivel de centralidad a las parroquias, así como incitando a la suburbanización de la clase alta en sus alrededores. De acuerdo con el Censo Nacional de Población y Vivienda del Ecuador año 2010, Cumbayá cuenta con una población de 31.463 habitantes (Gobierno Autónomo Descentralizado [GAD] Cumbayá, 2012) y Tumbaco contiene 49.944 habitantes (GAD Tumbaco, 2015). En total, la nueva centralidad Cumbayá-Tumbaco cuenta con 81.407 habitantes y una superficie de $92,13 \mathrm{~km}^{2}$.

Las características principales de Cumbayá-Tumbaco son: discontinuidades morfológicas, por tratarse de un espacio periurbano en constante desarrollo; población dispersa y en bajas densidades (barrios tradicionales, comunas, conjuntos habitacionales), configurada principalmente por estratos sociales altos y medios-altos; y "artefactos de la globalización" (centros comerciales, variedad de bienes y servicios) que atienden la demanda de todas las familias residentes en la parroquia (Instituto de la Ciudad, 2013). Por otro lado, el desarrollo alrededor del eje de la avenida Interoceánica es de suma importancia, por ser la conexión directa de Quito con la 
Amazonía Ecuatoriana y con el nuevo Aeropuerto Internacional de Tababela (a partir del año 2013), incrementando su articulación con la ciudad (GAD Tumbaco, 2015).

Por otro lado, analizamos la nueva centralidad de San Antonio de Pichincha, localizada en la zona centro norte del DMQ, a 13,5 kilómetros de la capital ecuatoriana. Se caracteriza por ser una centralidad turística en formación cuyo origen es el subcentro de San Antonio. El crecimiento de la población de manera desmesurada ha provocado que la distribución de predios en la parroquia sea dispersa y no consolidada.

San Antonio de Pichincha tiene una población de 32.357 habitantes (GAD San Antonio de Pichincha, 2012) y dispone de una superficie de $116,4 \mathrm{~km}^{2}$. Sus características más relevantes son su posición geográfica, por tratarse de la "mitad del mundo"; los sitios turísticos (museos y restaurantes), en especial el Museo Mitad del Mundo, que atrae turistas nacionales e internacionales; la proliferación de nuevos conjuntos residenciales, minicentros comerciales incorporados en los últimos años que abastecen las necesidades de la población local, y es sede de la Unión de Naciones Suramericanas (Unasur). Existe una diversidad de bienes y servicios en torno a la avenida Manuel Córdova Galarza, los cuales han dotado de un nivel de centralidad a la parroquia; además, presenta alta accesibilidad con la ciudad compacta de Quito, y este corredor es la única vía que conecta a la ciudad con el noroccidente hacia las provincias de Santo Domingo de los Tsáchilas y Esmeraldas.

\section{Zonas centrales en los casos en estudio}

Realizamos un análisis comparativo de ambos casos, el cual indica el desarrollo de una nueva centralidad en cada subcentro. Los resultados obtenidos muestran una zona central definida a lo largo del corredor terciario. Para el caso de CumbayáTumbaco (figura 2), se analizó la centralidad compuesta por 343 bienes y servicios, entre los que destacan centros comerciales, supermercados, hospitales, restaurantes, bares y cafeterías (tabla 4).

\begin{tabular}{|l|c|c|}
\hline \multicolumn{1}{|c|}{ NUEVA CENTRALIDAD } & CUMBAYÁ-TUMBACO & SAN ANTONIO \\
\hline Número de bienes y servicios & 343 & 128 \\
\hline$\%$ nivel centralidad & $75 \mathrm{al} 100$ & $75 \mathrm{al} 100$ \\
\hline Corredor terciario & Sí & Sí \\
\hline Número de bienes y servicios más centrales & 219 & 118 \\
\hline$\%$ servicios más centrales & 63,85 & 92,19 \\
\hline Área total $\left(\mathrm{km}^{2}\right)$ & 92,13 & 116,40 \\
\hline Área zona central $\left(\mathrm{km}^{2}\right)$ & 4,68 & 4,19 \\
\hline CMTC & 5,08 & 3,60 \\
\hline
\end{tabular}

TABLA 4 | Resultado análisis zonas centrales Cumbayá-Tumbaco y San Antonio FUENTE: ELABORACIÓN PROPIA

Por otro lado, San Antonio presentó únicamente 128 bienes y servicios para ser analizados, destacando entre ellos el monumento Mitad del Mundo, la sede de Unasur y el corredor terciario de la avenida Manuel Córdova Galarza, conformado por 
restaurantes, establecimientos de formación, micromercados, entre otros. Ambos casos están en proceso de expansión y denotan la importancia de que exista mayor número de bienes y servicios en Cumbayá-Tumbaco, ya que contiene la mayor población y el mayor desarrollo inmobiliario en la zona. Presentan igualmente aglomeración de bienes y servicios alrededor del corredor terciario. Al compararlos. se evidencia que Cumbayá-Tumbaco tiene una mayor Capacidad Máxima Territorial de Centralidad (смтс) (5,08\%) que San Antonio (3,6\%). Estos valores expresan el tamaño de la superficie central de cada caso y la influencia que ejerce sobre el entorno; por lo tanto, el área de influencia de Cumbayá-Tumbaco es mayor y -como se evidencia- las zonas de cobertura con nivel de centralidad abarcan más superficie que en San Antonio.

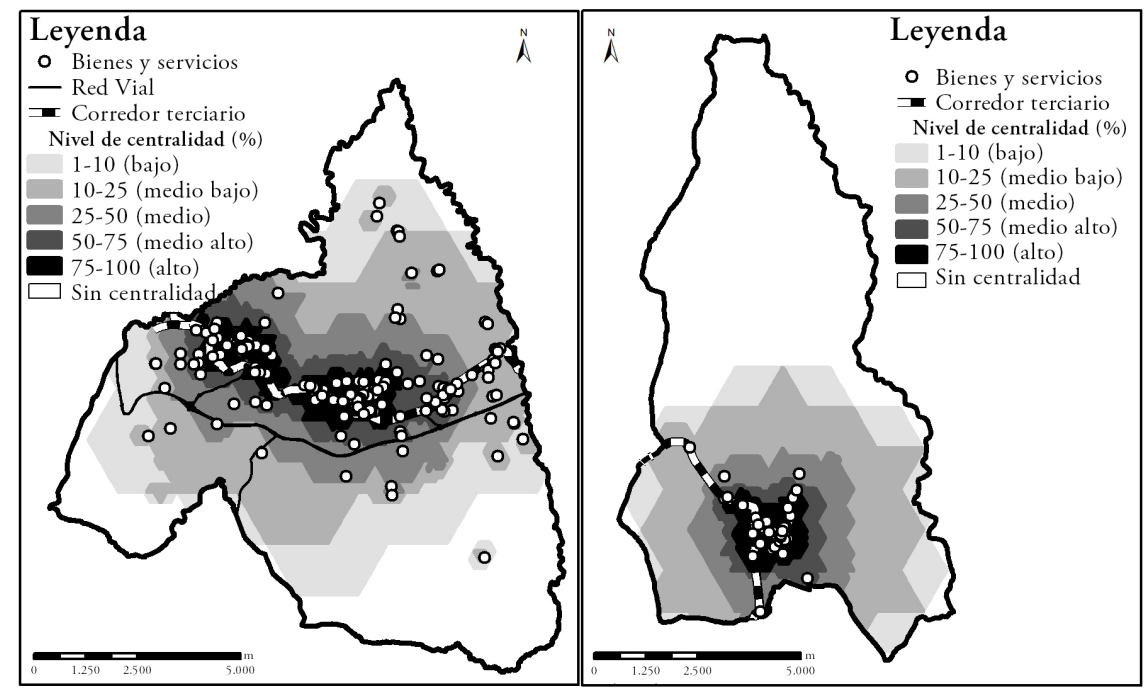

FIgURA 2 Niveles de centralidad de San Antonio

FUENTE: ELABORACIÓN PROPIA

Para el caso de Cumbayá-Tumbaco, el 63,85\% de los bienes y servicios se localiza en la zona central, lo que indica que no es necesario disponer de un $100 \%$ de ellos para alcanzar un nivel de centralidad alto. Al comparar con el 92,19\% de los bienes y servicios de San Antonio, se advierte que casi todos están agrupados en zonas con alto nivel de centralidad, aglomerados en el subcentro. A medida que la distancia aumenta desde la zona más central, el nivel de centralidad decrece hasta alcanzar zonas con bajo nivel de centralidad. Cumbayá-Tumbaco ha formado una centralidad extensiva y alargada, con buena cobertura alrededor del corredor terciario; allí la dispersión de bienes y servicios es mayor y tiene niveles de centralidad que van de medio a medio alto y alto en los subcentros. San Antonio ha conformado una centralidad concéntrica, con un núcleo definido y zonas con medio, medio alto y alto nivel de centralidad. Las áreas cíclicas que pierden centralidad están alejadas del corredor terciario y del subcentro. 
Ambas zonas centrales comparten el hecho de que tienen mayor centralidad en los subcentros y menor hacia los bordes; existe un corredor terciario, el cual es eje de la competencia por acceder a una mejor localización; el espacio con mayor centralidad contiene la mayoría de bienes y servicios y, por ende, mayor aglomeración de desarrollos inmobiliarios.

Discontinuidades morfológicas entre los años 2001 y 2010

Los dos casos en estudio presentan lugares con fragmentación (zonas rurales) y sin fragmentación espacial (zonas compactas en subcentros), que se han incrementado en el período 2001-2010 y se aglomeraron en torno a los subcentros y corredero terciario. Utilizando el indicador de densidad residencial, se analizaron 252 sectores censales en el caso Cumbayá-Tumbaco y 91 sectores en el caso San Antonio. Se determinó la proporción de fragmentos en función de la densidad residencial (tabla 5).

\begin{tabular}{|l|c|c|c|c|c|}
\hline \multirow{2}{*}{$\begin{array}{c}\text { ESTUDIO DE } \\
\text { CASO }\end{array}$} & \multirow{2}{*}{ AÑo } & \multicolumn{4}{|c|}{ FRAGMENTACIÓN ESPACIAL (PORCENTAJES) } \\
\cline { 3 - 6 } & ALTA & MEDIA & BAJA & $\begin{array}{c}\text { SIN } \\
\text { FRAGMENTACIÓN }\end{array}$ \\
\hline \multirow{2}{*}{$\begin{array}{c}\text { Cumbayá- } \\
\text { Tumbaco }\end{array}$} & 2001 & 87 & 11 & 2 & 1 \\
\cline { 2 - 6 } & 2010 & 69 & 21 & 9 & 1 \\
\hline \multirow{2}{*}{ San Antonio } & 2001 & 55 & 24 & 14 & 8 \\
\cline { 2 - 6 } & 2010 & 54 & 16 & 24 & 5 \\
\hline
\end{tabular}

TABLA 5 | Fragmentación espacial años 2001-2010 en Cumbayá-Tumbaco y San Antonio

FUENTE: ELABORACIÓN PROPIA

Para el primer caso (figura 3), se aprecia que el 87\% del territorio era altamente fragmentado hacia el año 2001, indicando que las parroquias de Cumbayá y Tumbaco fueron parroquias rurales con bajas densidades residenciales. Por otro lado, las zonas céntricas que corresponden a los subcentros consolidados son las de menor fragmentación espacial, abarcando un 2\% de fragmentos del territorio. Lo mismo ocurre para el segundo caso, donde un $55 \%$ de fragmentos corresponde a zonas rurales, mientras que un $24 \%$ de ellos tiene fragmentación espacial media. Existe un $14 \%$ de fragmentos localizados en zonas centrales, cuyas características indican un proceso de compactación, con un $8 \%$ ya compacto.

Se dieron cambios importantes hacia el año 2010, cuando en Cumbayá-Tumbaco y San Antonio se produjo el proceso de acumulación de capital que ha ocurrido en los subcentros. Muestra de ello es el incremento de urbanizaciones cerradas, grandes proyectos urbanos y variedad de bienes y servicios que han empezado a trasformar la morfología de las zonas.

Para el primer caso, Cumbayá-Tumbaco, el incremento de zonas atomizadas y dispersas (la fragmentación media aumenta a 21\%) señala que la densificación ocurre, y es interesante que se manifieste en el corredor terciario de la nueva centralidad. De igual manera, se incrementan las zonas de compactación desde el 2\% al $9 \%$, señalando una densificación del territorio, es decir, zonas con baja fragmentación espacial. 

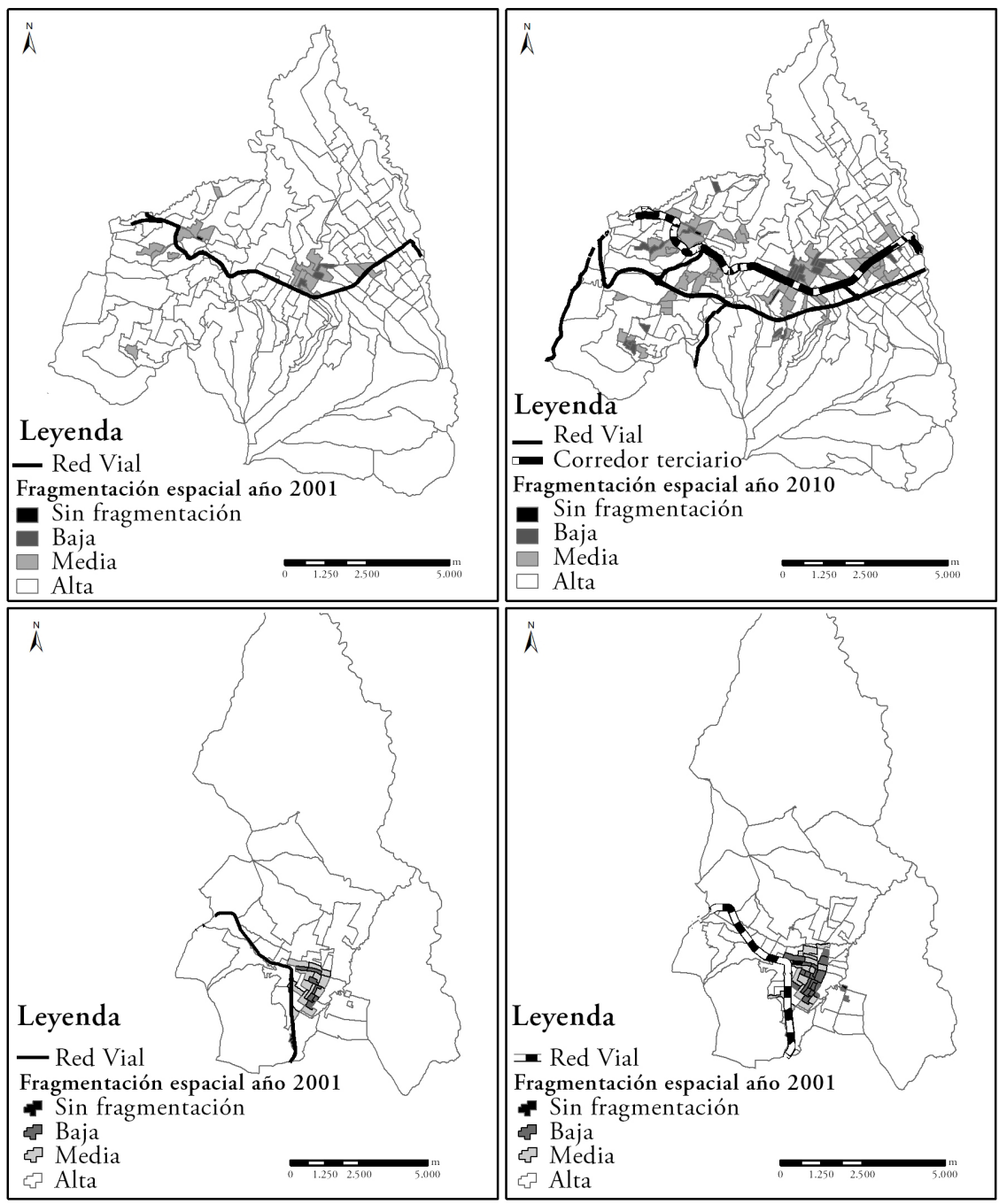

FIgURA 3 | Fragmentación espacial Cumbayá-Tumbaco (arriba) y San Antonio (abajo) años 2001-2010

FUENTE: ELABORACIÓN PROPIA

Para el segundo caso, San Antonio, ocurre que las zonas de mayor fragmentación (54\%) se mantienen sin cambios significativos; es decir, la parroquia sigue siendo zona rural. Las zonas atomizadas y dispersas se transforman en zonas en proceso de compactación, lo que indica una mayor densificación en el subcentro y baja fragmentación espacial.

En ambos casos, los subcentros y el corredor terciario son los que se densifican primero. Los bienes y servicios analizados también tienen mayor aglomeración en 
zonas centrales y contienen niveles de centralidad altos. Por otra parte, una mayor dispersión poblacional ocurre hacia las zonas externas al corredor terciario, que mantienen características rurales.

Distancia social entre los años 2001 y 2010

Para el año 2001 se obtuvo un indicador de distancia social, el cual ayuda a interpretar la presencia de fragmentación social. Para este indicador se analizaron 252 sectores censales en Cumbayá-Tumbaco y 91 en San Antonio. Lo que medimos fue el cambio de sectores censales en el tiempo y la proporción de los mismos para determinar la dispersión o aglomeración de las personas de acuerdo con su grado ocupacional (tabla 6).

\begin{tabular}{|l|c|c|c|c|}
\hline \multirow{2}{*}{ ESTUDIO DE CASO } & \multirow{2}{*}{ AÑo } & \multicolumn{3}{|c|}{ FRAGMENTACIÓN SOCIAL } \\
\cline { 2 - 5 } & & ALTA & MEDIA & BAJA \\
\hline \multirow{2}{*}{ Cumbayá-Tumbaco } & 2001 & $77 \%$ & $16 \%$ & $7 \%$ \\
\cline { 2 - 5 } & 2010 & $6 \%$ & $63 \%$ & $31 \%$ \\
\hline \multirow{2}{*}{ San Antonio } & 2001 & $73 \%$ & $14 \%$ & $14 \%$ \\
\cline { 2 - 5 } & 2010 & $8 \%$ & $66 \%$ & $26 \%$ \\
\hline
\end{tabular}

TABLA 6 | Fragmentación social años 2001-2010 en Cumbayá-Tumbaco y San Antonio

FUENTE: ELABORACIÓN PROPIA

Para el primer caso, Cumbayá-Tumbaco, hacia el año 2001 existía una fragmentación social alta en el $77 \%$ de los sectores analizados; esta característica corresponde a las zonas alejadas de los subcentros, que contienen población muy dispersa y presentan un entorno rural.

Se aprecia que un $7 \%$ de sectores localizados en zonas centrales y distribuidos a lo largo de la avenida Interoceánica (figura 4) presentan baja fragmentación social, debido a que existe alta aglomeración de personas con condiciones económicas similares (según su grado ocupacional), y es el sitio donde han proliferado desarrollos inmobiliarios. Un $16 \%$ de los sectores analizados contiene población menos dispersa y con concentraciones bajas de aglomeración; corresponden a zonas con fragmentación media, distribuidas a lo largo de la avenida señalada y alrededor de los subcentros Cumbayá y Tumbaco.

Para el caso San Antonio, se evidencia que un $73 \%$ de los sectores analizados contiene fragmentación social alta. Estos se distribuyen fuera del subcentro y rodean la avenida Manuel Córdova Galarza. Para el año 2001, San Antonio era altamente rural y las densidades residenciales eran muy bajas. Se encuentra un $14 \%$ de sectores con fragmentación baja, que corresponde a la aglomeración de personas de estratos económicos similares en el subcentro; y un 14\% de sectores con fragmentación media, localizados cerca del subcentro y la avenida seńalada. En ambos casos se repite la aglomeración de estratos similares en subcentros y dispersión de los mismos hacia la periferia. 


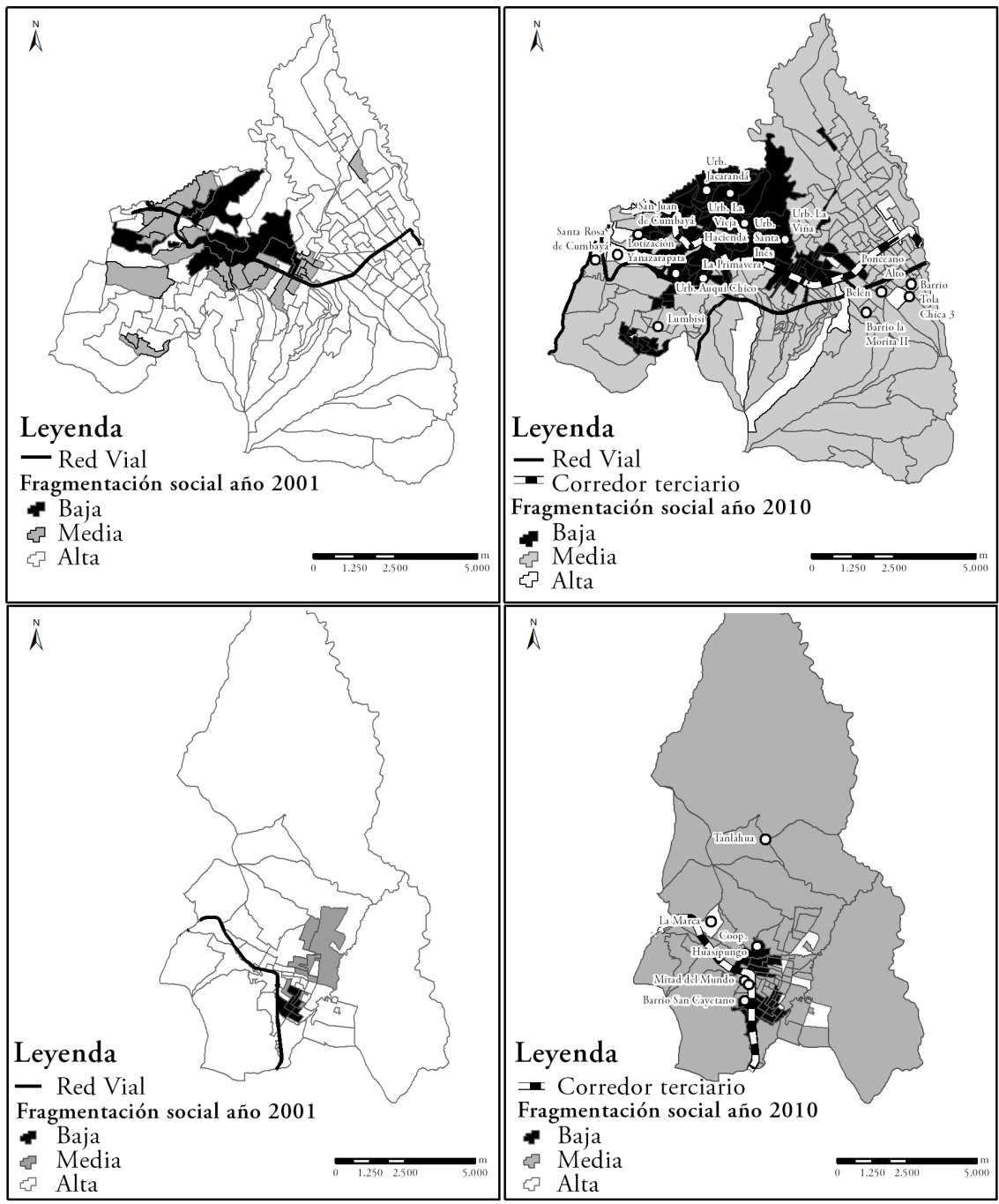

FIGURA 4 | Fragmentación social Cumbayá-Tumbaco (arriba) y San Antonio (abajo), años 2001-2010

FUENTE: ELABORACIÓN PROPIA

Para el ańo 2010, el panorama cambia en ambos casos. En el primero, se evidencia que la fragmentación social baja se incrementa a un 31\% de los sectores censales, lo que indica que el espacio se está homogeneizando y ha existido mayor aglomeración de estratos económicos similares. La característica principal de Cumbayá-Tumbaco es tratarse de una zona donde existe bastante desarrollo inmobiliario y urbanización de estratos económicos altos, destacando al respecto las urbanizaciones Jacarandá, La Vieja Hacienda, La Viña, Auqui Chico, La Primavera, entre otras. La fragmentación 
social media se incrementó al 66\% de los sectores censales, evidenciando que hay bajas concentraciones de estratos económicos similares; es decir, existe mayor heterogeneidad en la composición de los estratos en la zona, y corresponden a los barrios tradicionales alejados de los subcentros y nuevas lotizaciones que están surgiendo en Cumbayá y Tumbaco (Lumbisí, Barrios la Morita, Belén, Ponceano Alto, entre otros). Un $8 \%$ de los sectores contiene fragmentación social alta, y se trata de sitios puntuales donde existe un cambio brusco entre estratos sociales. Señalamos al respecto la urbanización Santa Inés, un territorio rodeado de conjuntos habitacionales cerrados y donde la mayoría es de estrato económico medio-bajo.

En el segundo caso, San Antonio, se presentan situaciones similares. Existe un incremento al 26\% de los sectores censales con fragmentación baja, distribuidos en el subcentro y alrededor del corredor terciario. Al igual que en el caso anterior, el desarrollo inmobiliario y la suburbanización aglomeran estratos de condiciones similares en los sitios más aventajados, con la diferencia de que son de clase media y media-baja. El 66\% de los sectores distribuidos alrededor del subcentro presenta fragmentación media. Se trata de bajas concentraciones de población con un estrato económico medio-bajo donde ya se marca la diferencia con el centro (sector de Tanlahua) en cuanto a condiciones de vida. Por otro lado, los espacios con fragmentación social alta se distribuyen hacia sitios menos centrales y alejados del subcentro. Se trata de zonas periféricas donde las urbanizaciones o barrios tradicionales se diferencian del territorio disperso que los rodea. Ello se evidencia en un $8 \%$ de los sectores, donde destacamos la urbanización La Marca, que contiene estratos sociales altos y cuya localización está anexa al corredor terciario.

En el análisis evidenciamos que, en ambos casos, las zonas de fragmentación baja abarcan los subcentros y el corredor terciario. La suburbanización y el desarrollo inmobiliario se apoderan de zonas centrales, con mejor ubicación y más accesibles, produciendo espacios socialmente homogéneos.

\section{Conclusiones}

El proceso de suburbanización desarrollado en las periferias de Quito durante el período analizado ha producido una acumulación de capital manifestada en nuevos proyectos inmobiliarios, centros comerciales, sitios turísticos y recreativos, así como variedad de bienes y servicios que se han aglomerado en los diferentes subcentros. La aglomeración ha significado dotar de niveles de centralidad a los corredores terciarios y sus alrededores.

Los altos niveles de centralidad están provocando que estratos sociales con mayores ventajas homogeneicen las zonas centrales y atomicen las zonas medianamente centrales. La expansión urbana continúa modificando la estructura urbana: lo que antes era una periferia altamente fragmentada ha disminuido con el tiempo, cambiando los patrones espaciales hacia un espacio periurbano medianamente fragmentado y en proceso de compactación.

El núcleo central contiene altos niveles de centralidad, siendo el sitio más accesible de las nuevas centralidades. Alrededor de la zona central las fronteras urbanas son menores, por tratarse de sitios compactos producidos por la densificación de 
la población y por la aglomeración de elementos que ocurren en dicho espacio. Las distancias sociales en este lugar también son bajas; se evidencian zonas suburbanizadas contenedoras de estratos sociales homogéneos, los cuales aprovechan las ventajas de la zona central, tanto en materia de bienes y servicios (oferta), como de localización, que facilita la conectividad con el centro de la ciudad.

La división territorial muestra la existencia de una menor fragmentación espacial en lugares céntricos, lo que redunda en un mayor tamańo de los espacios urbanizados. Este proceso también se evidencia en sitios con nivel de centralidad media, en los cuales se empiezan a evidenciar manchas urbanizadas en entornos rurales conectadas a la zona central a través de arterias viales, que articulan los fragmentos atomizados a los espacios consolidados.

A escala micro, el efecto de fragmentación es bajo: las distancias sociales se han reducido al punto de generar un espacio continuo. Los espacios cerrados producen una fractura del espacio a escala macro, ya que son notorios los cambios de la mancha urbanizada y se evidencian fragmentos con estratificación social diferenciada. Este efecto es negativo en cuanto a distancias sociales a escala macro, en cuanto la fragmentación continúa siendo parte del espacio periurbano.

La fragmentación espacial y la social generan un modelo periurbano difícil de delimitar, en el cual los lugares menos centrales producen un espacio atomizado, con bajas densidades residenciales y nuevos residentes localizados en barrios tradicionales. Se evidencia el proceso de urbanización en zonas rurales, lo que lleva a concluir que el espacio periurbano tiene una fragmentación socioespacial media, siendo así un sitio atomizado en proceso de compactación.

Como conclusión final, se puede argumentar que cuando una nueva centralidad se conforma, aglomera funciones especializadas en el periurbano. Mientras más especializada es la centralidad, más atractiva se convierte para quienes quieren usarla. Se trata de un espacio desarrollado entre fragmentos residenciales, reforzados por artefactos de la globalización que facilitan el intercambio comercial, ocio y entretenimiento, lo que hace que exista una vinculación entre fragmentos a través de las relaciones generadas. La distancia social es menor a escala micro, cuando nos adentramos en el fragmento; pero a escala macro se advierte un espacio fragmentado con partes diferenciadas.

Como hallazgo importante mencionamos que, en términos de la fragmentación social, es posible abrir nuevos caminos de investigación, puesto que la existencia de grupos sociales con características homogéneas que se ha detectado incita a pensar que existe un efecto de segregación en términos de estratos socioeconómicos (sobre todo en la centralidad Cumbayá-Tumbaco); y, a su vez, un desplazamiento de población local en el espacio periurbano producido por la acumulación de capital. 


\section{Referencias bibliográficas}

Abramo, P. (2012). La ciudad com-fusa: mercado y producción de la estructura urbana en las grandes metrópolis latinoamericanas. EURE, 38(114), 35-69. http://dx.doi. org/10.4067/S0250-71612012000200002

Acevedo, I. \& Velásquez, E. (2008). Algunos conceptos de la econometría espacial y el análisis exploratorio de datos espaciales. Ecos de Economía, (27), 9-34. http://publicaciones. eafit.edu.co/index.php/ecos-economia/article/view/705/627

Arteaga, I. (2005). De periferia a ciudad consolidada. Estrategias para la transformación de zonas urbanas marginales. Revista Bitácora Urbano Territorial, 9(1), 98-111. https:// www.redalyc.org/articulo.oa?id=74800909

Ávila, H. (2001). Ideas y planteamientos teóricos sobre los territorios periurbanos. Las relaciones campo-ciudad en algunos países de Europa y América. Investigaciones Geográficas, Boletín del Instituto de Geografia, 45, 108-127. https://doi.org/10.14350/rig.59148

Ávila, H. (2008). Periurbanización y espacios rurales en la periferia de las ciudades. Estudios Agrarios [Revista de la Procuraduría Agraria del Gobierno Federal Mexicano], 15(41), 93-123. http://www.pa.gob.mx/publica/rev_41/ANALISIS/7\%20HECTOR\%20AV ILA.pdf

Bazant, J. (2008). Proceso de expansión y consolidación urbana de bajos ingresos en las periferias. Bitácora Urbano Territorial, 13(2), Dossier Central), 117-132. https:// revistas.unal.edu.co/index.php/bitacora/article/view/18527/19437

Cagmani, R. (2005). Economía urbana. Barcelona: Antonio Bosch.

Caprón, G. \& González, S. (2006). Las escalas de la segregación y de la fragmentación urbana. Trace. Travaux et Recherches dans les Amériques du Centre, (49), 65-75. http://www. redalyc.org/articulo.oa?id=423839505006

Carrión, F. (2000). Centro histórico: relación social, globalización y mitos. En F. Carrión (ed.), Desarrollo cultural y gestión en centros históricos (pp. 179-192). Quito: Facultad Latinoamericana de Ciencias Sociales (Flacso), Sede Ecuador. http://www.flacso.org. ec/docs/sfdesculcarrion2.pdf

Carrión, F. (2003). Centros históricos y pobreza en América Latina. Mimeo, no publicado. Recuperado de http://www.flacso.org.ec/docs/fc_centrohisto.pdf

Ciccolella, P. (1999). Globalización y dualización en la Región Metropolitana de Buenos Aires. Grandes inversiones y reestructuración socioterritorial en los ańos noventa. EURE, 25(76), 5-27. http://dx.doi.org/10.4067/S0250-71611999007600001

Ciccolella, P. \& Mignaqui, I. (2009). Capitalismo global y transformaciones metropolitanas: enfoques e instrumentos para repensar el desarrollo urbano. En H. Poggiese \& T. T. Cohen Egler (comps.), Otro desarrollo urbano: ciudad incluyente, justicia social y gestión democrática (pp. 35-50). Buenos Aires: Consejo Latinoamericano de Ciencias Sociales (Clacso). http://bibliotecavirtual.clacso.org.ar/ar/libros/campus/poggiese/06cicco.pdf

Cortés, J. (2012). Diversidad de realidades mutables: bordes urbanos en límites naturales. Escenarios de cohesión social y preservación ambiental. Traza, 5, 120-145.

Cuenin, F. \& Silva, M. (2010). Identificación y fortalecimiento de centralidades urbanas: el caso de Quito. Notas Técnicas IDB-TN-156. Washington, D.C.: Banco Interamericano de Desarrollo (BID). https://publications.iadb.org/es/identificacion-y-fortalecimieto-decentralidades-urbanas-el-caso-de-quito 
Cuenya, B. (2011). Grandes proyectos y sus impactos en la centralidad urbana. Cadernos Metrópole, 13(25), 185-212. https://doi.org/10.1590/5987

De Mattos, C. (1999). Santiago de Chile, globalización y expansión metropolitana: lo que existía sigue existiendo. EURE, 25(76), 29-56. http://dx.doi.org/10.4067/S025071611999007600002

De Mattos, C. (2010). Globalización y metamorfosis metropolitana en América Latina. De la ciudad a lo urbano generalizado. Revista de Geografía Norte Grande, (47), 81-104. http://dx.doi.org/10.4067/S0718-34022010000300005

Díaz, F. (2011). Los territorios periurbanos de Córdoba: entre lo genérico y lo específico. Revista Iberoamericana de Urbanismo riURB, (5), 65-84. https://upcommons.upc.edu/ handle/2099/12500

Entrena-Durán, F. (2006). Difusión urbana y cambio social en los territorios rurales. Un estudio de caso en la Provincia de Granada. Revista de Estudios Regionales, (77), 179203. http://www.redalyc.org/articulo.oa?id=75507707

Escolano-Utrilla, S., López-Escolano, C. \& Pueyo-Campos, A. (2018). Urbanismo neoliberal y fragmentación urbana: el caso de Zaragoza (España) en los primeros quince años del siglo xxi. EURE, 14(132), 185-212. http://dx.doi.org/10.4067/s025071612018000200185

Frediani, J. (2009). Las nuevas periferias en el proceso de expansión urbana. El caso del partido de La Plata. Geograficando, 5(5), 103-125. http://www.memoria.fahce.unlp.edu.ar/ art_revistas/pr.4445/pr.4445.pdf

Gobierno Autónomo Descentralizado (GAD) Parroquial de Cumbayá (2012). Plan de Desarrollo y Ordenamiento Territorial de la Parroquia Cumbayá, 2012-2025. Quito: GAD Pichincha. https://ar.123dok.com/document/ozlg9lly-plan-de-desarrollo-yordenamiento-territorial-de-la-parroquia-cumbaya-2012-2025.html

Gobierno Autónomo Descentralizado (GAD) Parroquial de San Antonio de Pichincha (2012). Plan de Desarrollo y ordenamiento Territorial de la Parroquia San Antonio de Pichincha, 2012-2015. Quito: GAD Pichincha. https://studylib.es/doc/8370811/san-antonio--gad-provincia-de-pichincha

Gobierno Autónomo Descentralizado (GAD) de la Parroquia de Tumbaco (2015). Plan de Desarrollo y Ordenamiento Territorial de la Parroquia Tumbaco, 2012-2025. Quito: GAD Pichincha. https://es.scribd.com/document/334944814/PDOT-Tumbaco

Gallo, M., Garrido, R. \& Vivar, M. (2010). Cambios territoriales en la Comunidad de Madrid: policentrismo y dispersión. EURE, 36(107), 49-65. http://dx.doi.org/10.4067/ S0250-71612010000100001

Glendening, S. (2012). Delimiting the postmodern urban center: An analysis of urban amenity clusters in Los Angeles. Tesis de maestría en Ciencias, University of Southern California, Faculty of the usc Graduate School, California. http://digitallibrary.usc.edu/cdm/ref/ collection/p15799coll3/id/57565

Goldthorpe, J. (1993). Sobre la clase de servicio: su formación y su futuro. En F. de Carabaña \& A. de Francisco (eds.), Teorías contemporáneas de clases sociales (pp. 229-263). Madrid: Fundación Pablo Iglesias. 
Gutiérrez, J. \& García, J. (2007). La ciudad dispersa: Cambios recientes en los espacios residenciales de la comunidad de Madrid. Anales de Geografía de la Universidad Complutense, 27(1), 45-67. http://revistas.ucm.es/index.php/AGUC/article/viewFile/ AGUC0707110045A/30912

Harvey, D. (2012). Ciudades rebeldes. Del derecho de la ciudad a la revolución urbana. Madrid: Akal.

Hidalgo, R. \& Borsdorf, A. (2009). El crecimiento urbano en Europa: conceptos, tendencias y marco comparativo para el área metropolitana de Santiago de Chile. Estudios Geográficos, 70(266), 181-203. https://doi.org/10.3989/estgeogr.0449

Indovina, F. (2004). La ciudad difusa. En A. Ramos (coord.), Lo urbano en 20 autores contemporáneos (pp. 49-59). Barcelona: Universitat Politècnica de Catalunya / Escola Tècnica Superior d'Arquitectura de Barcelona.

Instituto de la Ciudad (2013). Sistemas rurales-urbanos en el DMQ. Quito: Instituto de la Ciudad / Sistema de investigación sobre la problemática agraria en el Ecuador (SIPAE). https:// www.academia.edu/35612901/Sistemas_rurales_urbanos_en_el_DMQ

Janoschka, M. (2002). El nuevo modelo de la ciudad latinoamericana: fragmentación y privatización. EURE, 28(85), 11-20. http://dx.doi.org/10.4067/S025071612002008500002

Jirón, P. \& Mansilla, P. (2014). Las consecuencias del urbanismo fragmentador en la vida cotidiana de los habitantes de la ciudad de Santiago de Chile. EURE, 40(121), 5-28. http://dx.doi.org/10.4067/S0250-71612014000300001

Katzman, R. \& Retamoso, A. (2005). Segregación espacial, empleo y pobreza en Montevideo. Revista de la CEPAL, 85 [LC/G.2266-P], 131-148. https://repositorio.cepal.org/ handle/11362/11004

Link, F. (2008). De la policentralidad a la fragmentación en Santiago de Chile. Revista de la Organización Latinoamericana y del Caribe de Centros Históricos, (2), 13-24. https:// biblio.flacsoandes.edu.ec/catalog/resGet.php?resId=14414

López, R., Gonzáles, F., Parrilla, E., Ruiz, J. \& Ruiz, T. (1996). Centros urbanos frente a nuevas centralidades comerciales: Un análisis del sur metropolitano de Madrid. Madrid: Instituto Juan Herrera.

Molinatti, F. (2013). Segregación residencial e inserción laboral en la ciudad de Córdoba. EURE, 39(117), 117-147. http://dx.doi.org/10.4067/S0250-71612013000200006

Muñiz, I., Sánchez, V. \& García-López, M. (2015). Estructura espacial y densidad de población en la zмvм 1995-2010: evolución de un sistema urbano policéntrico. EURE, 41(122), 75-102. http://dx.doi.org/10.4067/S0250-71612015000100004

Paris, M. (2013). De los centros urbanos consolidados a los lugares de centralidad: Una propuesta metodológica para su estudio. Ciudades [Revista del Instituto Universitario de Urbanística de la Universidad de Valladolid], 16(1), 47-69. http://uvadoc.uva.es/ handle/10324/10345

Pradilla, E. (2010). Mundialización neoliberal, cambios urbanos y políticas estatales en América Latina. Cadernos Metrópole, (12), 507-533. https://www.redalyc.org/ html/4028/402837809009/

Pradilla, E. \& Pino, P. (2004). Zona Metropolitana del Valle de México: de la centralidad a la red de corredores terciarios. Armario de espacios urbanos, 71-86. http://www. observatoriodasmetropoles.ufrj.br/Pradilla.pdf 
Prévôt-Schapira, M. (2001). Fragmentación espacial y social: conceptos y realidades. Perfiles Latinoamericanos [Revista de la Facultad Latinoamericana de Ciencias Sociales, Sede México], 9(19), 33-56. http://perfilesla.flacso.edu.mx/index.php/perfilesla/article/ view/315

Prévôt-Schapira, M. \& Cattaneo, R. (2008). Buenos Aires: la fragmentación en los intersticios de una sociedad polarizada. EURE, 34(103), 73-92. http://dx.doi.org/10.4067/ S0250-71612008000300004

Regidor, E. (2001). La clasificación de clase social de Goldthorpe: marco de referencia para la propuesta de medición de la clase social del grupo de trabajo de la Sociedad Española de Epidemiología. Revista Española de Salud Pública, 75(1), 13-22. http://www. mscbs.gob.es/biblioPublic/publicaciones/recursos_propios/resp/revista_cdrom/vol75/ vol75_1/RS751c_13.pdf

Rodríguez, J. (2012). ¿Policentrismo o ampliación de la centralidad histórica en el Área Metropolitana del Gran Santiago?: Evidencia novedosa proveniente de la encuesta Casen 2009. EURE, 38(114), 71-97. http://dx.doi.org/10.4067/S025071612012000200003

Rojas, E. (2004). La recuperación de áreas urbanas centrales. Problemas y soluciones. En E. Rojas (con la colaboración de E. Rodríguez V. \& E. Wegelin), Volver al centro: la recuperación de áreas urbanas centrales (pp. 1-41). Nueva York: Banco Interamericano de Desarrollo.

Rojas, C., Muñiz, I. \& García-López, M. (2009). Estructura urbana y policentrismo en el Área Metropolitana de Concepción. EURE, 35(105), 47-70. http://dx.doi.org/10.4067/ S0250-71612009000200003

Salcedo, R. \& Dear, M. (2012). La escuela de Los Ángeles y las metrópolis sudamericanas. Bifurcaciones. Revista de Estudios Culturales Urbanos, 11, 1-9. http://www.bifurcaciones. cl/2012/12/la-escuela-de-los-angeles-y-las-metropolis-sudamericanas/

Sheamur, R., Coffey, W., Dabé, C. \& Barbonne, R. (2007). Intrametropolitan employment structure: polycentricity, scatteration, dispersal and chaos in Toronto, Montreal and Vancouver, 1996-2001. Urban Studies, 44(9), 1713-1738. http://dx.doi. org/10.1080/00420980701426640

Secretaría de Territorio, Hábitat y Vivienda, Ecuador. (2012). Plan Metropolitano de Ordenamiento Territorial 2012-2022. Quito: Municipio de Quito. https://bit. ly/1Sbi9XY

Soja, E. W. (2000). Exópolis. La reestructuración de la forma urbana. En E. Soja, Postmetrópolis. Estudios criticos sobre las ciudades y las regiones (pp. 333-367). Madrid: Traficantes de Sueños. https://bibliodarq.files.wordpress.com/2014/08/2_soja-e-w-exopolis-la-reestr ucturacic3b3n-de-la-forma-urbana.pdf

Tella, G. (2005). Ínsulas de riqueza en océanos de pobreza o el proceso de fragmentación territorial de buenos aires. Scripta Nova, 9(194-50), 1-11. http://dx.doi.org/10.1344/ sn2005.9.966

Toro, C., Velasco, V. \& Niño, A. (2005). El borde como espacio articulador de la ciudad actual y su entorno. Revista Ingenierías Universidad de Medellín, 4(7), 55-65. http://www. redalyc.org/pdf/750/75004705.pdf 